Cite this: Phys. Chem. Chem. Phys., 2013,

\title{
High-temperature isothermal chemical cycling for solar-driven fuel production
}

15, 17084

Received 9th June 2013, Accepted 5th August 2013

DOI: $10.1039 / \mathrm{c} 3 \mathrm{cp} 53270 d$

www.rsc.org/pccp

\author{
Yong Hao, ${ }^{\text {ab }}$ Chih-Kai Yang ${ }^{a}$ and Sossina M. Haile ${ }^{a}$
}

\section{Introduction}

It has recently been demonstrated that ceria $\left(\mathrm{CeO}_{2}\right)$ and its derivatives (e.g., rare-earth doped ceria) can be used effectively in solar-driven two-step thermochemical cycles for the production of $\mathrm{H}_{2}$ and/or $\mathrm{CO}$ from $\mathrm{H}_{2} \mathrm{O}$ and/or $\mathrm{CO}_{2}{ }^{1-7}$ The reaction scheme, as written out explicitly for the case of $\mathrm{H}_{2}$ production from $\mathrm{H}_{2} \mathrm{O}$, is given as

$$
\begin{aligned}
& \text { (Higher temperature, } \left.T_{\mathrm{H}}\right) \\
& \frac{1}{\delta_{\text {red }}-\delta_{\mathrm{ox}}} \mathrm{CeO}_{2-\delta_{\mathrm{ox}}} \rightarrow \frac{1}{\delta_{\text {red }}-\delta_{\mathrm{ox}}} \mathrm{CeO}_{2-\delta_{\text {red }}}+\frac{1}{2} \mathrm{O}_{2}(\mathrm{~g})
\end{aligned}
$$

(Lower temperature, $T_{\mathrm{L}}$ )

$$
\mathrm{H}_{2} \mathrm{O}(\mathrm{g})+\frac{1}{\delta_{\text {red }}-\delta_{\text {ox }}} \mathrm{CeO}_{2-\delta_{\text {red }}} \rightarrow \frac{1}{\delta_{\text {red }}-\delta_{\text {ox }}} \mathrm{CeO}_{2-\delta_{\text {ox }}}+\mathrm{H}_{2}(\mathrm{~g})
$$

$$
\text { Total } \mathrm{H}_{2} \mathrm{O}(\mathrm{g}) \rightarrow \frac{1}{2} \mathrm{O}_{2}(\mathrm{~g})+\mathrm{H}_{2}(\mathrm{~g})
$$

where $\delta_{\text {red }}$ and $\delta_{\text {ox }}$ are the oxygen nonstoichiometry of ceria at equilibrium under thermal reduction (eqn (1)) and thermochemical oxidation (eqn (2)), respectively. To date, full demonstrations

\footnotetext{
${ }^{a}$ Materials Science, California Institute of Technology, Pasadena, CA 91125, USA

${ }^{b}$ Institute of Engineering Thermophysics, Chinese Academy of Sciences, Beijing,

100190, China. E-mail: haoyong@iet.cn
}

incorporating such a strategy have validated the technological viability of the approach, but efficiencies in the solar-to-fuel conversion process have been limited to a few per cent. ${ }^{7,8}$ While such values are significant in light of the infancy of this technology, substantial advances are necessary for true commercial viability. To this end, considerable efforts are being directed towards the design of reactors that provide inherently higher efficiencies. A key issue is the recovery of heat from the reactive oxide, which, by definition of the two-temperature cycle, undergoes temperature swings of several hundred degrees. Reactor designs incorporating strategies for solid state heat recovery have been proposed and are under development, ${ }^{9,10}$ however, maintaining dimensional stability of high temperature moving parts, as required by these designs, has proven daunting. ${ }^{11}$ Given the inherent challenges of solid state heat recovery, it is valuable to consider thermochemical approaches to solar fuel production that eliminate the large temperature swing of the solid phase. We present here precisely such an approach. ${ }^{12}$

It is well known that with increasing temperature, the dissociation of steam to hydrogen and oxygen becomes increasingly favored, that is, thermolysis occurs. ${ }^{13}$ Thus, steam at high temperature is in equilibrium with a higher partial pressure of oxygen than it is at low temperature, and, as a consequence, steam is effectively more oxidizing at high temperature than at low temperature. Recognizing this characteristic, we explore here an isothermal cycle in which ceria is held at high temperature and is sequentially exposed to (1) inert gas with low oxygen 


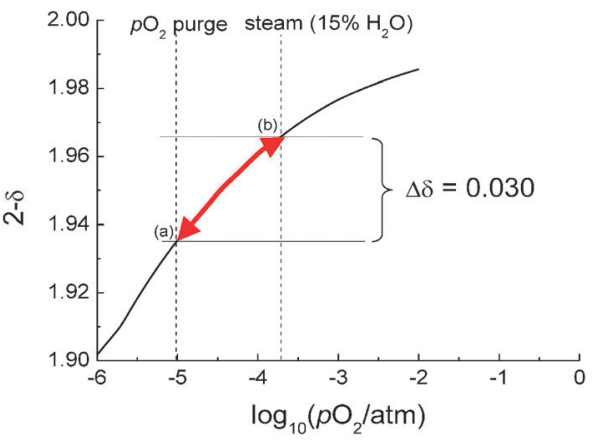

Fig. 1 Isothermal cycling strategy overlain on oxygen non-stoichiometry of $\mathrm{CeO}_{2-\delta}$ at $1500{ }^{\circ} \mathrm{C}$, the latter after Panlener. ${ }^{15}$ Example shown here is for reduction under an inert gas stream with $10 \mathrm{ppm}$ (residual) oxygen and hydrolysis under $0.15 \mathrm{~atm}$ steam, implying a theoretical $\Delta \delta$ as shown and a fuel productivity of $4.0 \mathrm{ml} \mathrm{H}$ (standard pressure and temperature, STP) per gram of ceria. Labels (a) and (b) stand for the reduced and oxidized states of ceria, respectively.

partial pressure, a step which reduces the oxide, and (2) steam, the reaction with which releases hydrogen. The reactions are formally identical to those given in eqn (1) and (2) above, but with $T_{\mathrm{L}}=T_{\mathrm{H}}$. Using as an example the measured non-stoichiometry of ceria at $1500{ }^{\circ} \mathrm{C}$, the cycle can be understood as proceeding between positions (a) and (b) in Fig. 1.

In contrast to a two-temperature approach, the isothermal process fundamentally relies on the reducing potential of the inert gas in addition to the oxidizing potential of steam. Furthermore, because the driving force for the oxidation of the ceria is lower at high temperature than it is at low temperature, one can expect that the fuel produced per cycle of the isothermal strategy will be lower than that of the conventional, two-temperature cycle. On the other hand, one can also anticipate substantial system simplifications under isothermal operation as a result of the elimination of solid-state heat recovery as a requirement for high efficiency. In addition, the reactor can be designed to minimize heat losses without repercussions in terms of difficulty in removing heat to reach a low temperature for the hydrolysis step. In order to achieve high efficiency in the high-temperature isothermal cycle, heat recovery from the fluid phase, which is now cycled over a very wide temperature window, can be expected to become extremely important. That is, in moving from a two-temperature to an isothermal strategy, the burden of heat recovery is shifted from the solid to the fluid phase, where the latter is a more tractable problem with demonstrated technological solutions. ${ }^{14}$ The aim of this work is to provide a preliminary analysis of the conditions that can potentially result in high-efficiency cycling as well as to present preliminary data demonstrating the viability of this new strategy.

\section{Analytical methodology}

A numerical study was undertaken to evaluate the efficiency characteristics of the proposed cycle. The objective is to evaluate the plausibility of the proposed cycling strategy rather than to provide an in-depth analysis of any particular configuration. The latter would require detailed knowledge of the configuration of

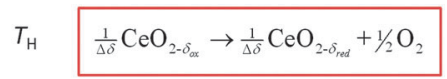

(2)

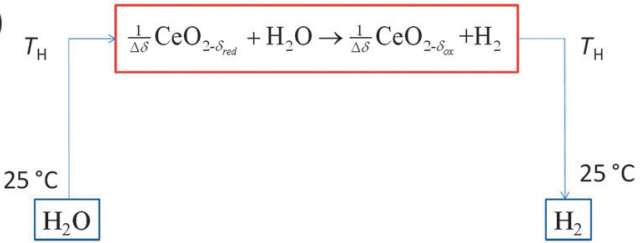

Fig. 2 Schematic of isothermal cycling showing the steps in the overall process.

the reactor in which the process is performed, as well as the kinetic and microstructural properties of the material, aspects which are premature to establish for an initial analysis. For the present purposes we take the kinetics to be infinitely fast in order to consider the material thermodynamics limit under assumed global behavior of the reactor. The overall process is broken up into the two steps shown in Fig. 2. The first step is the high temperature reduction of ceria, and the second step, with three parts, is the process of heating steam to the temperature at which the first step is performed, reacting it with the reduced ceria, and then cooling the generated hydrogen back to room temperature.

The thermodynamic efficiency of the solar-to-fuel conversion process is simply the ratio between the energy content of the fuel produced to the input solar energy. Assuming the hydrogen energy content to correspond to its higher heating value (HHV, $285.8 \mathrm{~kJ} \mathrm{~mol}^{-1}$ ) and performing the calculation on a per-mole-ofhydrogen basis, the efficiency is ${ }^{6}$

$$
\eta_{\text {solar-fuel }}=\frac{285.8 \mathrm{~kJ}}{Q_{\text {solar }}}
$$

where $Q_{\text {solar }}$ is the total solar energy input required to produce one mole of hydrogen. For the process described in Fig. 2, $Q_{\text {solar }}$ consists of (1) the heat input to reduce ceria at the operational temperature and (2) that required to vaporize water and heat steam to the reaction temperature, modulated by the solar absorption efficiency. For notational convenience and consistency with our previous work ${ }^{6}$ we consider the ceria non-stoichiometry at the initiation of the oxidation half-cycle to be the initial value $\left(\delta_{i}\right)$. For a change in ceria nonstoichiometry of $\Delta \delta=\delta_{i}-\delta_{f}$ upon reduction (where $\delta_{f}$ is the final value), the first term is

$$
Q_{\text {redu }}=\frac{-1}{\Delta \delta} \int_{\delta_{f}}^{\delta_{i}} \Delta H_{\text {ceria }}(\delta) \mathrm{d} \delta
$$

where $\Delta H_{\text {ceria }}(\delta)$ is the oxidation enthalpy of ceria, defined on a per mole of (atomic) oxygen basis. ${ }^{15}$ To vaporize and heat $n_{\mathrm{H}_{2} \mathrm{O}}$ moles of water/steam from $25{ }^{\circ} \mathrm{C}$ to the operational temperature, $T$, the required heat input (i.e. the second term) is

$$
\begin{aligned}
& Q_{\mathrm{H}_{2} \mathrm{O}} \\
& =n_{\mathrm{H}_{2} \mathrm{O}}\left(\int_{25^{\circ} \mathrm{C}}^{10{ }^{\circ} \mathrm{C}} C_{p, \mathrm{H}_{2} \mathrm{O}(\mathrm{l})} \mathrm{d} T+\Delta H_{\mathrm{H}_{2} \mathrm{O}(\mathrm{O}) \rightarrow(\mathrm{g})}^{10{ }^{\circ} \mathrm{C}}+\int_{100^{\circ} \mathrm{C}}^{T} C_{p, \mathrm{H}_{2} \mathrm{O}(\mathrm{g})} \mathrm{d} T^{\prime}\right)
\end{aligned}
$$


where $n_{\mathrm{H}_{2} \mathrm{O}}$ is the number of moles of $\mathrm{H}_{2} \mathrm{O}, \Delta H_{\mathrm{H}_{2} \mathrm{O}(\mathrm{l}) \rightarrow(\mathrm{g})}^{100}$ is the molar latent heat of vaporization of $\mathrm{H}_{2} \mathrm{O}$ at its boiling point under $1 \mathrm{~atm}$, and $C_{p, \mathrm{H}_{2} \mathrm{O}(\mathrm{l})}$ and $C_{p, \mathrm{H}_{2} \mathrm{O}(\mathrm{g})}$ are, respectively, the molar heat capacities of the liquid and the vapor phase $\mathrm{H}_{2} \mathrm{O}$ at constant pressure. $^{16}$

From the perspective of mass balance just one mole of water is required to produce one mole of hydrogen and hence $n_{\mathrm{H}_{2} \mathrm{O}}$ in eqn (6) is just equal to 1 . Thermodynamic considerations, however, dictate that the number of moles required to reach a target value of $\delta_{f}$ is generally greater than $n_{\mathrm{H}_{2} \mathrm{O}}=\Delta \delta n_{\mathrm{CeO}_{2-\delta i}}$. On the other hand, increasing the moles of $\mathrm{H}_{2} \mathrm{O}$ delivered to the reactor will increase the input enthalpy, potentially without increasing the fuel produced. To allow for and explore the consequences of varying the quantity of $\mathrm{H}_{2} \mathrm{O}$, the calculations were performed using $r_{\mathrm{H}_{2} \mathrm{O}}=n_{\mathrm{H}_{2} \mathrm{O}} / \delta_{i} n_{\mathrm{CeO}_{2-\delta_{i}}}$ as a variable. Specifically, $\delta_{i}$ was first taken as an input from the initial equilibration in the reduction step, assuming an open system with fixed $p_{\mathrm{O}_{2}}$. The value of $\delta_{f}$ was then computed for each value of $r_{\mathrm{H}_{2} \mathrm{O}}$ assuming a closed system of variable size and a fixed pressure of $p_{\mathrm{H}_{2} \mathrm{O}}=1 \mathrm{~atm}$. The quantity of fuel produced is simply $\Delta \delta$. Evaluation of $\delta_{i}$ and $\delta_{f}$ was achieved using the thermodynamic data reported for the reduction of ceria. ${ }^{15}$ Specifically, Panlener et al. have determined the enthalpy and entropy terms in the expression

$$
\Delta G(\delta, T)=\Delta H(\delta)-T \Delta S(\delta)=R T \ln p_{\mathrm{O}_{2}}
$$

over the $\delta$ range from $1.07 \times 10^{-3}$ to 0.27 and the temperature range 750 to $1500{ }^{\circ} \mathrm{C}$, where the temperature dependence is found to be negligible. Inverting eqn (7) for the $p_{\mathrm{O}_{2}}$ under reduction yields $\delta_{i}$, whereas a closed-system equilibrium analysis using the given $r_{\mathrm{H}_{2} \mathrm{O}}$ and the thermodynamic properties of water ${ }^{16}$ in combination with eqn (7) yields $\delta_{f}{ }^{6}$

The sum of the enthalpy inputs required to achieve the chemical and thermal changes described above, eqn (5) and (6), is denoted simply $Q_{\mathrm{TC}}$. Beyond these direct heating requirements, the inefficiencies of the solar absorption process must also be accounted for. Assuming the reactor cavity to behave as a blackbody receiver and further assuming perfect solar collector optics, the losses due to solar absorption inefficiencies imply an increase in the solar energy input beyond the sum of the enthalpy inputs for the chemical and thermal transformations according to

$$
Q_{\text {solar }}=\frac{Q_{\mathrm{TC}}}{\eta_{\mathrm{abs}}(T, C)}
$$

where the absorption efficiency, $\eta_{\mathrm{abs}}$, is a function of both $T$ and concentration ratio $C .^{13}$ Re-radiation losses are then simply given as

$$
Q_{\text {rerad }}=Q_{\text {solar }}-Q_{\mathrm{TC}}=\left(\eta_{\mathrm{abs}^{-1}}{ }^{-1}\right) Q_{\mathrm{TC}} .
$$

We take $C=5000$, corresponding to an incident radiation flux of $5 \mathrm{MW} \mathrm{m}{ }^{-2}$.

In an operational reactor, low-partial-pressure oxygen premix in inert gases is used to set the oxygen chemical potential in the gas phase and flush released oxygen away in the reduction step. Such inert gases will also require heating, but assessment of these enthalpy inputs requires detailed knowledge of the quantity of carrier gas required per mole of hydrogen produced, requiring, in turn, detailed knowledge of the reactor gas flow dynamics and materials microstructure. More importantly, the use of inert gases can be replaced by mechanical pumping to achieve identical functionalities mentioned above, for which the work consumption is negligible compared with that of the total solar energy input. For example, to pump 0.5 moles of oxygen from $10^{-5}$ atm to $1 \mathrm{~atm}$ (in order to produce 1 mole of hydrogen), the work consumption $\left(W=n R T \ln \left(p_{\mathrm{atm}} / p_{\mathrm{O}_{2}}\right)\right)$ is $14.26 \mathrm{~kJ}$, corresponding to $0.2 \%$ or $1.1 \%$ of the total solar energy input at $1500{ }^{\circ} \mathrm{C}$ with $0 \%$ or $90 \%$ heat recovery from water, respectively. For this reason and to facilitate a materialsfocused analysis we omit the inert gas heating term. Doing so also permits a direct comparison with previous analyses in which this inert gas heating requirement was similarly omitted. ${ }^{6,17,18}$

In contrast to the amount of inert carrier gas utilized, the quantity of steam utilized is set as an input parameter and thus it is possible to directly evaluate the impact of heating and cooling $\mathrm{H}_{2} \mathrm{O}$ (or cooling product gases, $\mathrm{O}_{2}$ and $\mathrm{H}_{2}$ ). In addition, because gas phase heat recovery is a demonstrated technology, it is valuable to explore the influence its implementation would have on the overall solar-to-fuel conversion efficiency. The process is treated here simply by defining $f$ as the fractional reduction in the amount of input heat required to achieve high temperature steam as a result of heat recovery from the exhaust gases. In this way, $Q_{\mathrm{H}_{2} \mathrm{O}}$ is redefined as $Q_{\mathrm{H}_{2} \mathrm{O}}{ }^{\prime}=(1-f) Q_{\mathrm{H}_{2} \mathrm{O}}$. By this definition, $f$ is not precisely the fraction of heat recovered from the exiting gases because the heat capacity of oxygen and hydrogen does not precisely sum to the heat capacity of steam, but it provides a sufficiently close approximation in light of other assumptions. With this definition, and ignoring the potential for solid state heat recovery from the ceria oxidation step, eqn (2), we arrive at the final expression for the solar input:

$$
Q_{\text {solar }}=\frac{\left[(1-f) Q_{\mathrm{H}_{2} \mathrm{O}}+Q_{\text {redu }}\right]}{\eta_{\text {abs }}(T, C)}, \quad 0 \leq f<1
$$

The numerical procedure was implemented using an in-house Python code.

\section{Computational results}

The first parameters explored are $r_{\mathrm{H}_{2} \mathrm{O}}$ and $T$, with no heat recovery, where $r_{\mathrm{H}_{2} \mathrm{O}}$, again, is the molar ratio of input $\mathrm{H}_{2} \mathrm{O}$ $\left(n_{\mathrm{H}_{2} \mathrm{O}}\right)$ to oxygen vacancies in the reduced ceria $\left(\delta_{i} n_{\mathrm{CeO}_{2-\delta_{i}}}\right)$. A base-case of efficiency as a function of $r_{\mathrm{H}_{2} \mathrm{O}}$ is presented in Fig. 3, for temperatures in the range from 1500 to $1900{ }^{\circ} \mathrm{C}$. Along with this are presented an evaluation of the component enthalpy inputs, $Q_{\mathrm{H}_{2} \mathrm{O}}, Q_{\text {redu }}$, and $Q_{\text {rerad }}$, for the limiting case of very low $r_{\mathrm{H}_{2} \mathrm{O}}\left(=10^{-4}\right)$, Fig. 4 , and the dependence of the extent of $\mathrm{H}_{2} \mathrm{O}$ conversion to $\mathrm{H}_{2}$ (conversion rate) on $r_{\mathrm{H}_{2} \mathrm{O}}$, Fig. 5, for the various temperatures represented in Fig. 3.

Two efficiency trends clearly emerge. First, the efficiency increases with temperature. Second, for each temperature, the efficiency monotonically increases with decreasing $r_{\mathrm{H}_{2} \mathrm{O}}$, approaching a temperature-dependent limiting value as $r_{\mathrm{H}_{2} \mathrm{O}} \rightarrow 0$. 


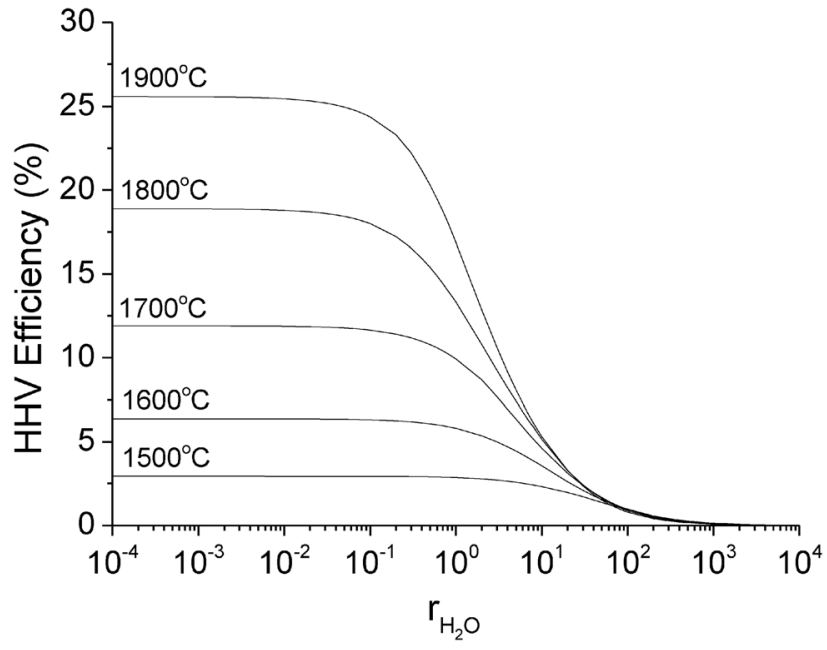

Fig. $3 \mathrm{HHV}$ efficiency of ceria isothermal cycling versus water-vacancy ratio $r_{\mathrm{H}_{2} \mathrm{O}}$ without heat recovery.

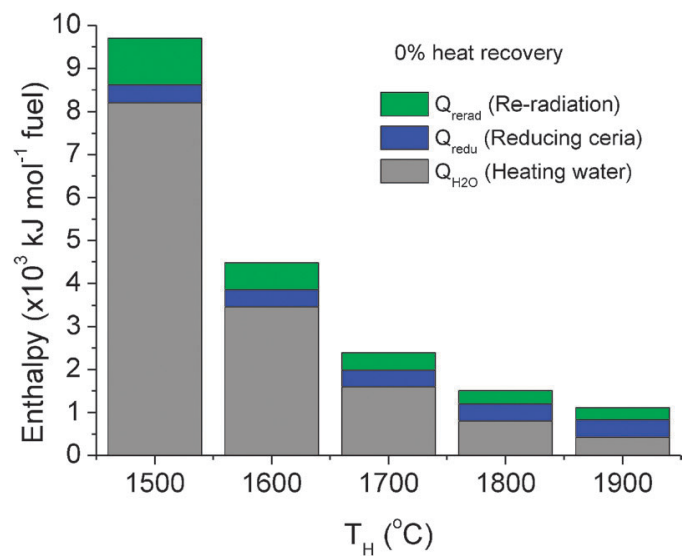

Fig. 4 Components of the total enthalpy input necessary for the production of 1 mole of $\mathrm{H}_{2}$ without heat recovery for $r_{\mathrm{H}_{2} \mathrm{O}}=10^{-4}$.

These trends can be understood on the basis of the behavior captured in Fig. 4 and 5. Specifically, it is apparent that $Q_{\mathrm{H}_{2} \mathrm{O}}$ is the dominant enthalpy input at all temperatures, with its magnitude monotonically decreasing with increasing temperatures, Fig. 4. This decrease results because thermolysis depends exponentially on temperature through the dissociation reaction

$$
\mathrm{H}_{2} \mathrm{O} \leftrightarrow \mathrm{H}_{2}+\frac{1}{2} \mathrm{O}_{2} ; \quad K_{\mathrm{H}_{2} \mathrm{O}}=\frac{P_{\mathrm{H}_{2}} P_{\mathrm{O}_{2}}^{\frac{1}{2}}}{P_{\mathrm{H}_{2} \mathrm{O}}}=\exp \left(\frac{-\Delta G^{\theta}}{k_{\mathrm{b}} T}\right)
$$

where $\Delta G^{\theta}$ is the standard free energy of the reaction and $k_{\mathrm{b}}$ is Boltzman's constant. Thus, each incremental increase in temperature produces an ever greater extent of $\mathrm{H}_{2} \mathrm{O}$ dissociation and ever greater thermodynamic driving force to oxidize the reduced ceria and release hydrogen. Consequently, less and less $\mathrm{H}_{2} \mathrm{O}$ is required to achieve a given final non-stoichiometry $\left(\delta_{f}\right)$ and thereby to generate a given amount of fuel. A smaller amount of $\mathrm{H}_{2} \mathrm{O}$ implies a proportional decrease in $Q_{\mathrm{H}_{2} \mathrm{O}}$. In contrast, the enthalpy input required for ceria reduction is virtually independent of temperature. This reflects the fact that

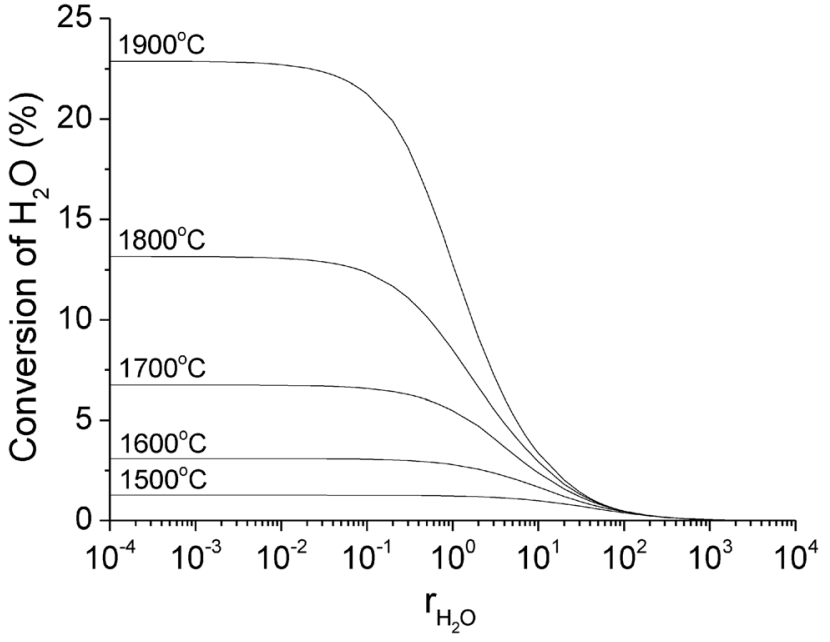

Fig. 5 Percentage of $\mathrm{H}_{2} \mathrm{O}$ converted to $\mathrm{H}_{2}$ as a function of the water-vacancy ratio $r_{\mathrm{H}_{2} \mathrm{O}}$ at selected temperatures.

$\Delta H(\delta)$ is itself independent of temperature, ${ }^{15}$ and that the range of $\delta$ spanned over the cycle, between $\delta_{i}$ and $\delta_{f}$, is relatively small such that the slight dependence of $\Delta H$ on $\delta$ does not play a significant role. The third term, $Q_{\text {rerad }}$, decreases slightly with increasing temperature. This is a simple consequence of the fact that the reradiation losses are proportional to the sum of all of the other enthalpy inputs (eqn (9)). In sum, just as in twotemperature cycling, efficiency monotonically increases with increasing operating temperature, with the operational limits being largely set by the properties of the reactor housing materials rather than the efficiency benefits afforded by the reactive oxide.

Turning to the dependence on $r_{\mathrm{H}_{2} \mathrm{O}}$, one observes that the efficiency, Fig. 3, tracks almost precisely the $\mathrm{H}_{2} \mathrm{O}$ conversion rate, Fig. 5. The latter, in turn, reflects the competing thermodynamics of $\mathrm{H}_{2} \mathrm{O}$ thermolysis, and ceria reduction and the dependence of $\eta$ on $r_{\mathrm{H}_{2} \mathrm{O}}$ can be understood as follows. In the limit of very high water input $\left(r_{\mathrm{H}_{2} \mathrm{O}} \rightarrow \infty\right)$ the vapor phase effectively becomes, as a result of thermolysis, an infinite source of oxygen atoms, and its composition is unchanged by reaction with ceria. This results in a conversion that falls to zero. The extent to which ceria can be oxidized by this infinite source is, in fact, finite, with a final nonstoichiometry $\delta_{f}^{*}$ dictated by the oxygen partial pressure of the steam. Excess steam beyond that required to convert $\mathrm{CeO}_{2-\delta_{i}}$ to $\mathrm{CeO}_{2-\delta_{f^{*}}}$ will simply add to the $Q_{\mathrm{H}_{2} \mathrm{O}}$ budget without yielding additional $\mathrm{H}_{2}$ such that the efficiency falls to zero.

In the converse limit $\left(r_{\mathrm{H}_{2} \mathrm{O}} \rightarrow 0\right)$, ceria now acts as an infinite sink for incorporating oxygen from the gas phase, without noticeable impact on the ceria non-stoichiometry and thus on the chemical potential of oxygen within the ceria. Although $\delta_{f} \approx \delta_{i}$ in this limit, the conversion of steam to hydrogen is finite, and the reaction comes to an end when the gas-phase chemical potential of oxygen falls to the value of the chemical potential of oxygen within the ceria, that is, when $\mu_{\mathrm{O}}^{\text {gas,final }}=$ $\mu_{\mathrm{O}}^{\text {ceria }}\left(\delta_{i}\right)$. Because $\delta_{i}$ is obtained by equilibration with a gas of known oxygen partial pressure, this equality can be rewritten as 
$p_{\mathrm{O}_{2}}$ (steam, final $)=10^{-5}$ atm. Regardless of the total amount of $\mathrm{H}_{2} \mathrm{O}$ supplied, attaining a given $\mu_{\mathrm{O}}^{\text {gas,final }}$ at a given temperature requires conversion of a fixed fraction of $\mathrm{H}_{2} \mathrm{O}$ to $\mathrm{H}_{2}$, thus, the conversion tends to a constant value. The temperature dependence of the limiting value of $r_{\mathrm{H}_{2} \mathrm{O}}$ arises from the fact that, due to thermolysis, $\mu_{\mathrm{O}}^{\text {gas,initial }}$ increases with temperature, and thus a greater fraction of $\mathrm{H}_{2} \mathrm{O}$ must be converted to reach the unchanged value of $\mu_{\mathrm{O}}^{\text {gas,final }}$. For isothermal operation, there is no penalty for utilizing greater and greater quantities of oxide and hence the fixed conversion in the $r_{\mathrm{H}_{2} \mathrm{O}} \rightarrow 0$ limit translates into a fixed efficiency. Realistically, however, one cannot expect the efficiency to remain high as $r_{\mathrm{H}_{2} \mathrm{O}}$ tends to zero because maintaining a large quantity of reactive oxide at high temperature is unlikely to be possible without some heat losses. In addition, ever greater quantities of carrier gas would be required relative to the number of moles of $\mathrm{H}_{2} \mathrm{O}$ and any heat losses due to less than $100 \%$ heat recovery from this gas would also be increasingly significant as $r_{\mathrm{H}_{2} \mathrm{O}} \rightarrow 0$.

The results in Fig. 4 emphasize the potential for increasing efficiency by heat recovery from exiting steam and product gases, $\mathrm{H}_{2}$ and $\mathrm{O}_{2}$. The extent to which $f$, where $f$ represents the efficacy of heat recovery (eqn (10)), can influence overall efficiency is illustrated in Fig. 6 for the case in which $r_{\mathrm{H}_{2} \mathrm{O}}=$ $10^{-4}$. As would be expected, efficiency increases monotonically with increasing extent of heat recovery. Significantly, the results suggest that attractive efficiencies may be possible in isothermal cycling given a combination of sufficiently high temperature operation and sufficiently large $f$.

The overall dependence of efficiency on $r_{\mathrm{H}_{2} \mathrm{O}}$ in the case of non-zero heat recovery, Fig. 7 , is similar to that in which no heat is recovered (Fig. 3) but the upper-limit efficiency (as $r_{\mathrm{H}_{2} \mathrm{O}} \rightarrow 0$ ) becomes significantly higher for all temperatures. Another noticeable difference in Fig. 7 compared to Fig. 4 is that the flat, high-efficiency region of $r_{\mathrm{H}_{2} \mathrm{O}}$ becomes wider, with the turning point around $r_{\mathrm{H}_{2} \mathrm{O}}=1$. This value is technically meaningful, for the isothermal cycle can be operated with just the right amount of material, both steam and oxide. It reflects the fact that the ceria is easily reoxidized.

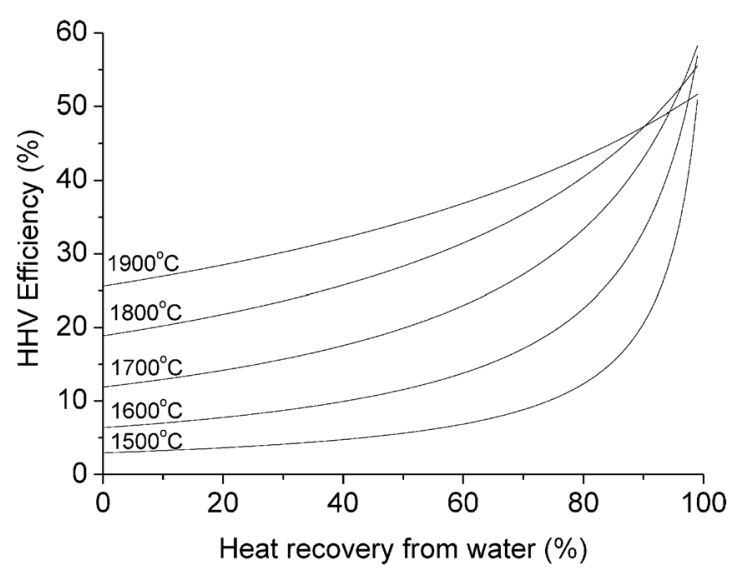

Fig. 6 Maximum HHV efficiency of ceria isothermal cycling versus heat recovery percentage from water $\left(r_{\mathrm{H}_{2} \mathrm{O}}=10^{-4}\right)$ in the range from 0 to $99 \%$.

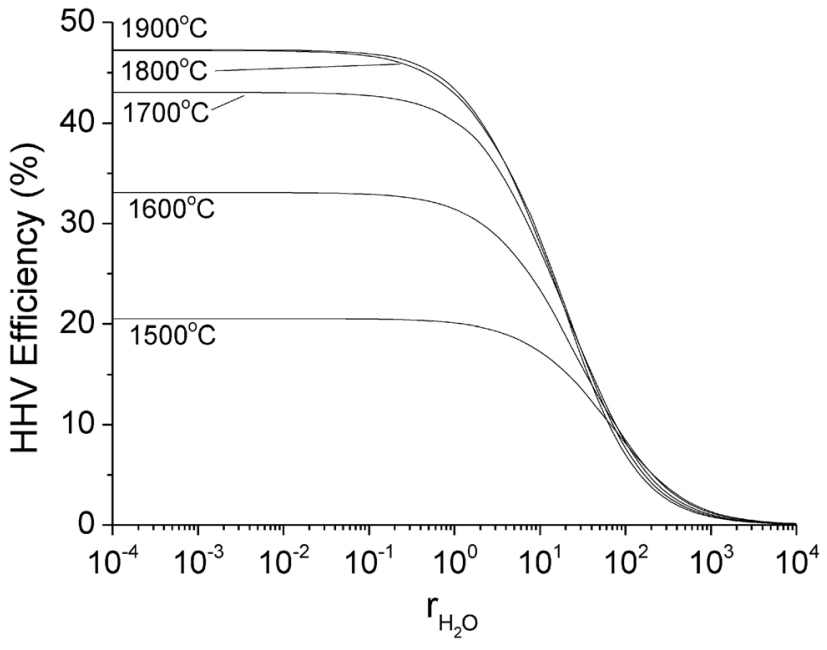

Fig. $7 \mathrm{HHV}$ efficiency of ceria isothermal cycling versus water-vacancy ratio $r_{\mathrm{H}_{2} \mathrm{O}}$ with effective $90 \%$ heat recovery $(f=0.9)$.

In contrast to the zero heat recovery case, increasing temperature, while beneficial in the low temperature regime, does not lead to further increase in efficiency beyond $1800{ }^{\circ} \mathrm{C}$. This is because the decrease in the energy cost for heating water, $(1-f) Q_{\mathrm{H}_{2} \mathrm{O}}$, is eventually outweighed by the increase of $\eta_{\text {abs }}{ }^{-1}$ (Table 1). This turnover occurs at lower temperatures with heat recovery than without simply because the efficiencies are much higher.

With high levels of heat recovery, the enthalpy budget in the low- $r_{\mathrm{H}_{2} \mathrm{O}}$ limit, Fig. 8, reflects the fact that, by definition, $Q_{\mathrm{H}_{2} \mathrm{O}}$ is small, and hence the enthalpy inputs are dominated by that required to reduce ceria. As in the case of no heat recovery, efficiency increases with temperature because less and less $\mathrm{H}_{2} \mathrm{O}$ is required per mole of $\mathrm{H}_{2}$ produced as a result of the increasing oxidizing power of $\mathrm{H}_{2} \mathrm{O}$ with increasing temperature. In this case, however, there is an upper limit within the temperature range explored and efficiency ultimately plateaus at the highest temperatures due to the reradiation losses already discussed.

With this backdrop, it is of value to compare the efficiency of isothermal cycling to that of two-temperature cycling. For the latter, the efficiency is calculated using the procedures outlined in ref. 6 , in which the enthalpy input for raising the temperature of ceria from $T_{\mathrm{L}}$ to $T_{\mathrm{H}}$ is accounted for in addition to the $Q_{\mathrm{TC}}$ described above in eqn (5) and (6). We further allow for the possibility of both solid state and gas phase heat recovery. Again, heat recovery is treated simply by reducing the enthalpy input to achieve a given $\Delta T$ by a fraction, $f$. While more detailed analyses have appeared in the literature, ${ }^{19}$ the methods pursued here are sufficient for the purpose of comparing the two cycling strategies. Representative results are presented in Fig. 9 as a function of $T_{\mathrm{H}}$ in which the $r_{\mathrm{H}_{2} \mathrm{O}}$ values are $10^{-4}$ and $2,{ }^{6}$ respectively,

Table 1 Solar receiver efficiency $\eta_{\text {abs }}$ at a concentration level of 5000

\begin{tabular}{llllllll}
\hline & $1300{ }^{\circ} \mathrm{C}$ & $1400{ }^{\circ} \mathrm{C}$ & $1500{ }^{\circ} \mathrm{C}$ & $1600{ }^{\circ} \mathrm{C}$ & $1700{ }^{\circ} \mathrm{C}$ & $1800{ }^{\circ} \mathrm{C}$ & $1900{ }^{\circ} \mathrm{C}$ \\
\hline$\eta_{\text {abs }}$ & 0.931 & 0.911 & 0.888 & 0.860 & 0.828 & 0.791 & 0.747
\end{tabular}




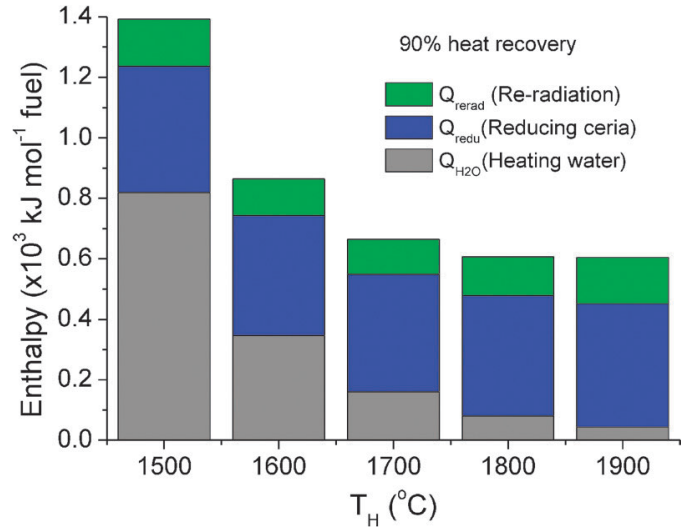

Fig. 8 Components of the total energy spent on producing 1 mole of $\mathrm{H}_{2}$ with $90 \%$ heat recovery for $r_{\mathrm{H}_{2} \mathrm{O}}=10^{-4}$.

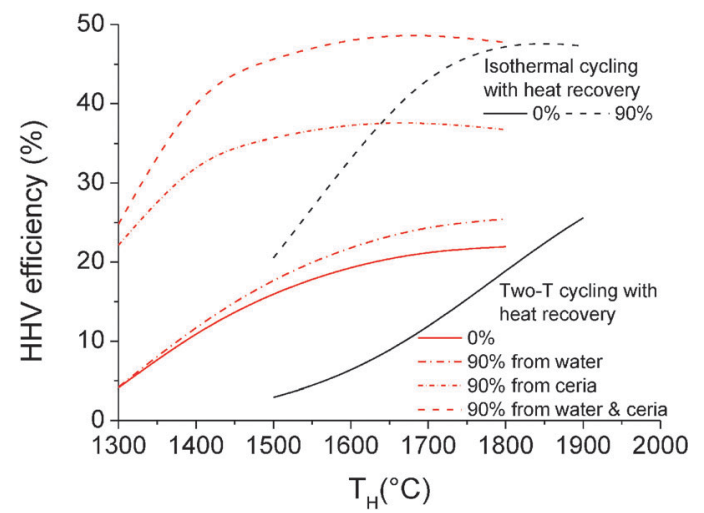

Fig. $9 \mathrm{HHV}$ efficiencies of isothermal $\left(r_{\mathrm{H}_{2} \mathrm{O}}=10^{-4}\right)$ and two-T cycling $\left(r_{\mathrm{H}_{2} \mathrm{O}}=2\right.$, where maximum $\mathrm{HHV}$ efficiency is achieved) with $0 \%$ and $90 \%$ heat recovery.

for the isothermal and two-temperature calculations, and, additionally, the $T_{\mathrm{L}}$ in the latter case is that which yields, within the $r_{\mathrm{H}_{2} \mathrm{O}}$ and $T_{\mathrm{H}}$ constraints, the overall maximum HHV efficiency. ${ }^{6}$ Several important trends are evident. First, in the absence of heat recovery (solid curves), the overall efficiencies are low, as expected. Moreover, two-temperature cycling is more efficient than isothermal cycling for all but the highest temperatures. Introduction of heat recovery increases the efficiency of both approaches, while generally leaving two-temperature cycling as the preferred process at low temperatures. The conditions under which two-temperature cycling becomes advantageous over isothermal cycling depend sensitively on the components of the heat recovery. Specifically, heat recovery from the gas phase alone has only a slight impact on efficiency, leaving isothermal efficiency preferable at all temperatures above $\sim 1400{ }^{\circ} \mathrm{C}$. In contrast, if both solid state and gas phase heat recovery can be implemented with high efficacy, two-temperature cycling is more efficient. Conversely, even with very high levels of heat recovery, isothermal cycling is inefficient at low temperatures (below about $1300{ }^{\circ} \mathrm{C}$ ); this results because the sweep gas does not have sufficient reducing power to create a significant $\delta_{i}$, and because the steam generated at this temperature does not have sufficient oxidizing power to result in a $\delta_{f}$ that is much lower than $\delta_{i}$. While the precise temperatures at which one strategy becomes more efficient than the other will depend on a variety of details not considered here, the general trends provide guidance regarding the relative advantages and disadvantages of the two approaches.

\section{Experimental studies}

With promising numerical results in hand, an experimental study to evaluate the overall viability of the isothermal cycling strategy was carried out.

\subsection{Procedures}

Fine powder of undoped ceria was synthesized by dissolving 0.12 mole of $\mathrm{Ce}\left(\mathrm{NO}_{3}\right)_{3} \cdot 6 \mathrm{H}_{2} \mathrm{O}$ (Alfa Aesar) in deionized water, followed by the addition of $0.18 \mathrm{~mol}$ of ethylenediaminetetraacetic acid and citric acid (Alfa Aesar) of each to a constantly-stirred Teflon beaker. To this $125 \mathrm{ml}$ of $\mathrm{NH}_{4} \mathrm{OH}$ was added to achieve $\mathrm{pH}=10$. The solution was then heated to and maintained at $80^{\circ} \mathrm{C}$ on a hot plate and stirred at $400 \mathrm{rpm}$ until gelation. The resulting product was transferred to an alumina crucible (CoorsTek; 99.9\% purity), gently heated to $300{ }^{\circ} \mathrm{C}$ to evolve organics, and then calcined at $350{ }^{\circ} \mathrm{C}$ for $2 \mathrm{~h}$ in air. These procedures yield a singlephase fluorite-type product as demonstrated by X-ray powder diffraction (not shown).

Highly porous $(\sim 80 \%$ porosity $)$ cylinders of the above materials were prepared as follows. The powders were loosely consolidated by first wetting with isopropanol then lightly pressing while in a die. The resulting green bodies were sintered at $1500{ }^{\circ} \mathrm{C}$ for $2 \mathrm{~h}$ under stagnant air. Selected samples were loaded with $\mathrm{Rh}$ using an impregnation method. ${ }^{6}$ The porous cylindrical samples were dipped into an aqueous solution of $\mathrm{Rh}\left(\mathrm{NO}_{3}\right)_{3} \cdot 2 \mathrm{H}_{2} \mathrm{O}$ (5.25 wt\% concentration), and the entirety of the sample was instantaneously wetted due to capillary action. The samples were removed, dried in ambient air for $10 \mathrm{~min}$, and subsequently calcined at $750{ }^{\circ} \mathrm{C}$ for $2 \mathrm{~h}$ in stagnant air. Weight measurements before and after showed the $\mathrm{Rh}$ content to be approximately $2 \mathrm{wt} \%$.

For fuel productivity measurements, samples $(0.3-0.5 \mathrm{~g}$ in mass) were placed individually in an alumina tube reactor and located in the uniform hot zone of a ULVAC-RIKO infrared imaging furnace. Reduction was carried out under $10 \mathrm{ppm} p_{\mathrm{O}_{2}}$ in $\operatorname{Ar}\left(1000 \mathrm{ml} \mathrm{min}^{-1}\right.$ at standard temperature and pressure (STP); $139 \mathrm{~cm} \mathrm{~s}^{-1}$ at $1500{ }^{\circ} \mathrm{C}$ ) and hydrolysis under $p_{\mathrm{H}_{2} \mathrm{O}}=$ $0.15 \mathrm{~atm}\left(200 \mathrm{ml}\right.$ Ar per min and $35 \mathrm{ml} \mathrm{H}_{2} \mathrm{O}$ per min at STP; total of $33 \mathrm{~cm} \mathrm{~s}^{-1}$ at $1500{ }^{\circ} \mathrm{C}$ ). By no means was the latter step, the reaction between steam and reduced ceria, performed in a closed system; the very large values of $r_{\mathrm{H}_{2} \mathrm{O}}$ in the experimental configuration were aimed at achieving detectable gas production rather than creating a thermally efficient process. Exhaust gases were detected and analyzed online using a Pfeiffer Thermostar mass spectrometer. The ion current values recorded using the mass spectrometer were converted to gas concentrations using a six-point calibration procedure for $\mathrm{H}_{2}$ and a four-point calibration procedure for $\mathrm{O}_{2}$. For various experimental reasons, determination of absolute $\mathrm{H}_{2}$ values 
was not possible in some cases, and the raw ion current results are converted, in those instances, to implied absolute values based on the $\mathrm{O}_{2}$ evolution. The calculation is performed under the assumption that the integrated per cycle yields of $\mathrm{H}_{2}$ and $\mathrm{O}_{2}$ occur in a 2:1 molar ratio, an assumption that is justified, as shown below, by the reproducibility of the oxygen release profiles.

\subsection{Results}

An example of a set of $\mathrm{H}_{2}$ and $\mathrm{O}_{2}$ evolution profiles obtained under isothermal cycling of undoped ceria without a catalyst at $1500{ }^{\circ} \mathrm{C}$ is shown in Fig. 10 . The results provide clear evidence that, despite the small thermodynamic driving force for stoichiometric changes under isothermal conditions, fuel production is possible. Detection of oxygen prior to the point at which the gas is changed from steam to Ar purge is attributed to either a small oxygen leak, which becomes evident when the hydrogen concentration falls, and/or quenching of the hydrolysis reaction, induced by the very fast cooling from the point of exhaust from the furnace to the point of contact with the ice bath. Returning to the behavior of the oxide, as expected from the overall reduction characteristics of ceria, Fig. 5, fuel productivity $\left(\mathrm{H}_{2}\right.$ per mass of oxide per cycle) increases monotonically with temperature, Fig. 11.

In the experiments represented in Fig. 10 and 11 the halfcycle times (Ar flush and $\mathrm{H}_{2} \mathrm{O}$ exposure) were held fixed at $10 \mathrm{~min}$ each. It was found that an increase in reduction time, while retaining the hydrolysis time at $10 \mathrm{~min}$, led to an increase in oxygen release, Fig. 12. The oxygen release profiles, presented for several different periods of reduction, Fig. 12(a), overlap one another almost precisely, suggesting that the hydrolysis step has returned the oxide to the same level of oxidation irrespective of the period of reduction. Slight differences in the profiles are attributed to evolution of the microstructure, with the very first profile showing an initial (or peak) oxygen release rate of $1.23 \mathrm{ml} \mathrm{min}^{-1} \mathrm{~g}^{-1}$ and the final profile, acquired after a total of 22 cycles and 423 minutes of exposure to $1500{ }^{\circ} \mathrm{C}$, showing a value of $1.03 \mathrm{ml} \mathrm{min}^{-1} \mathrm{~g}^{-1}$. Additional slight differences in the integrated oxygen yield values result from the high sensitivity of

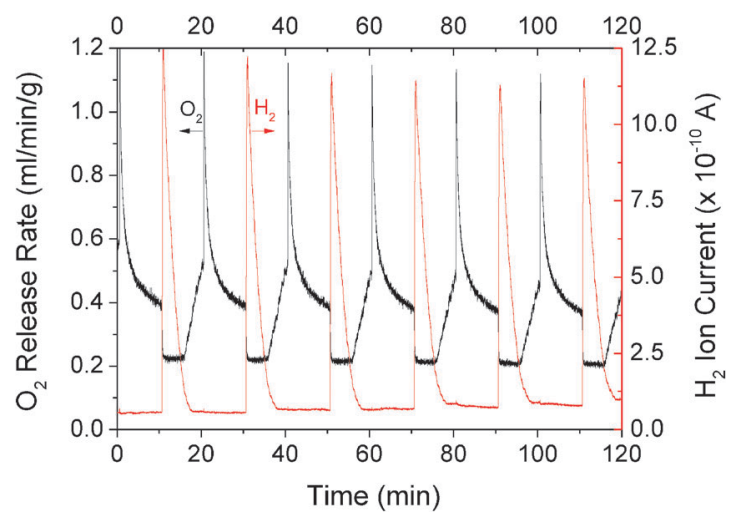

Fig. $10 \mathrm{O}_{2}$ production rate and corresponding $\mathrm{H}_{2}$ ion current for isothermal thermochemical cycling with pure ceria at $1500{ }^{\circ} \mathrm{C}$. Time for reduction $\left(p_{\mathrm{O}_{2}}=\right.$ $\left.10^{-5} \mathrm{~atm}\right)$ and oxidation $\left(p_{\mathrm{H}_{2} \mathrm{O}}=0.15 \mathrm{~atm}\right)$ half cycles is 10 minutes, respectively.

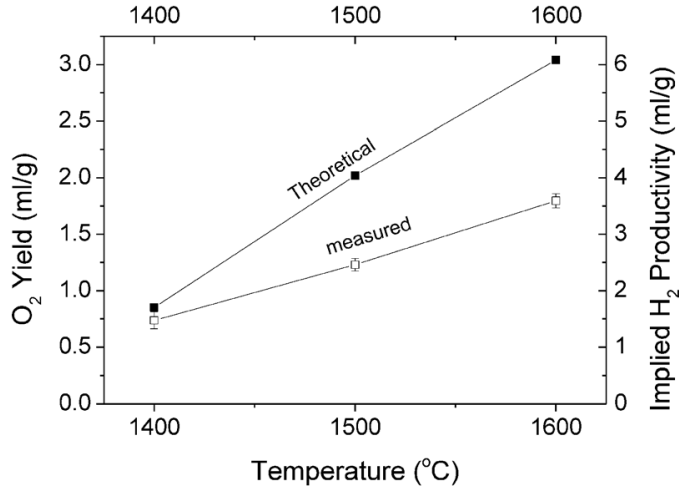

Fig. 11 The as-measured $\mathrm{O}_{2}$ yield using undoped ceria for isothermal thermochemical cycling at 1400,1500 and $1600{ }^{\circ} \mathrm{C}$ with reduction and hydrolysis times each being 10 minutes. The theoretical $\mathrm{O}_{2}$ yield assuming full equilibration for $p_{\mathrm{O}_{2}}=10^{-5} \mathrm{~atm}$ (reduction) and $p_{\mathrm{H}_{2} \mathrm{O}}=0.15 \mathrm{~atm}$ (hydrolysis) is calculated from ref. 15 and shown for comparison. The implied $\mathrm{H}_{2}$ productivity is shown by the vertical axis on the right.

the integration to the baseline positioning given the small signal-to-noise ratio. These experimental uncertainties not withstanding, the high degree of overlap of the profiles in Fig. 12(a) suggests that ten minutes is sufficient to fully reoxidize ceria to the non-stoichiometry value indicated under steam in Fig. 1, but that even twenty minutes of exposure to inert gas undoubtedly does not achieve the non-stoichiometry value indicated under $p_{\mathrm{O}_{2}}$ purge. By fitting an exponential decay function to the 20-minute oxygen release profile in Fig. 12(a), acquired after stabilization of the microstructural evolution, we compute the anticipated $\mathrm{H}_{2}$ productivity as a function of thermal reduction time shown in Fig. 12(b). The asymptotic limit of the hydrogen productivity, $3.1 \mathrm{ml} \mathrm{g}^{-1}$, falls somewhat short of the thermodynamic equilibrium value of $4.0 \mathrm{ml} \mathrm{g}^{-1}$. The difference between these two values reflects the challenges of detecting product gases that are evolved at low rates.

The Rh catalyst has a surprising influence on the thermochemical reaction rates. The relatively fast hydrolysis step is enhanced by application of the catalyst, Fig. 13 . The peak rate in hydrogen production at $1500{ }^{\circ} \mathrm{C}$ is approximately $50 \%$ higher in the presence of $\mathrm{Rh}$, whereas the time constant of the exponential decay of the $\mathrm{H}_{2}$ profile is approximately halved (1.4 s vs. $3.1 \mathrm{~s}$ ). This result indicates that surface reaction rather than bulk oxygen diffusion is rate-limiting for high-temperature hydrolysis, as it is at the lower temperatures of two-temperature cycling. ${ }^{20}$ In contrast to hydrolysis, the relatively slow reduction step shows, at best, a slight enhancement in the presence of the catalyst, Fig. 14. Because it is unlikely that the rate-limiting step has changed to being bulk diffusion (diffusion distances are on the order of a few micrometers and the chemical diffusion coefficient is at least $10^{-6} \mathrm{~cm}^{2} \mathrm{~s}^{-1}$ (ref. 21)), this surprising result indicates that the surface step, although rate-limiting for oxygen release, is not substantially enhanced by $\mathrm{Rh}$.

It is of some value to compare the fuel production rate of isothermal cycling to that of two-temperature cycling in a fashion analogous to that in which the thermodynamics were compared. Based on the experimental observation of trends in 
(a)

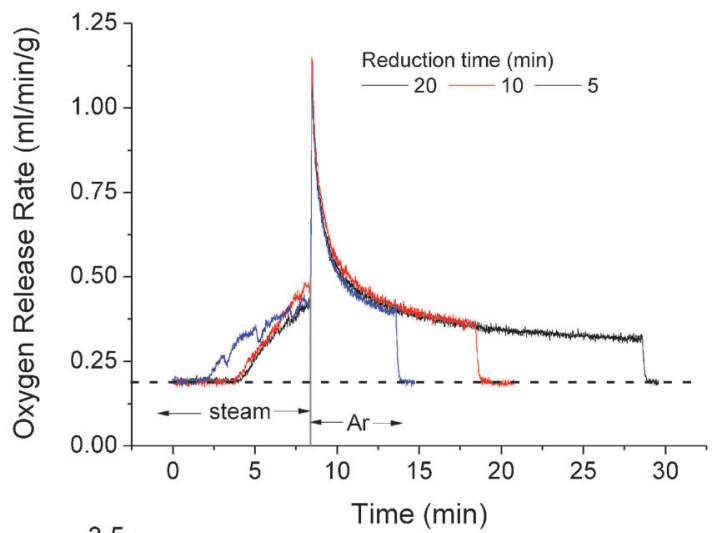

(b)

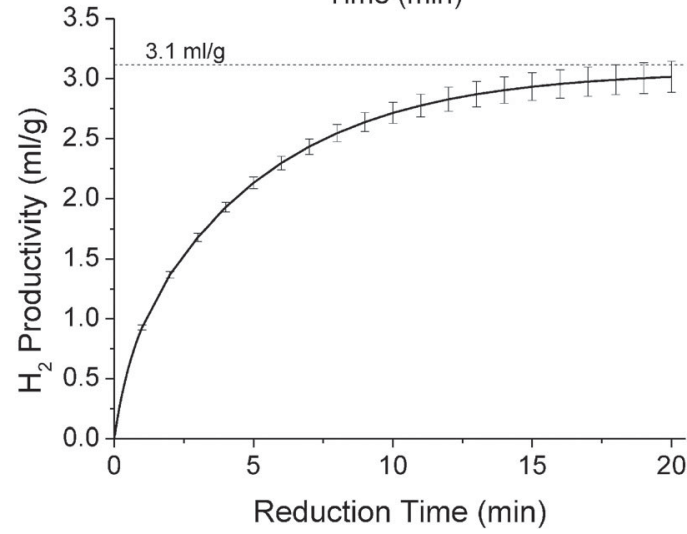

Fig. 12 Effect of reduction time on $\mathrm{H}_{2}$ production from ceria for isothermal thermochemical cycling at $1500{ }^{\circ} \mathrm{C}$. (a) Selected $\mathrm{O}_{2}$ release profiles for different reduction times ( $p_{\mathrm{O}_{2}}=10^{-5} \mathrm{~atm}$, balance $\mathrm{Ar}$, up to $20 \mathrm{~min}$ ) and a fixed $10 \mathrm{~min}$ period of hydrolysis $\left(p_{\mathrm{H}_{2} \mathrm{O}}=0.15 \mathrm{~atm}\right.$, balance $\mathrm{Ar}$ ); (b) implied $\mathrm{H}_{2}$ productivity versus reduction time determined from an exponential decay fit to the $20 \mathrm{~min} \mathrm{O}_{2}$ profile in (a), with error bars indicating the range of measured variation for 20 min reduction.

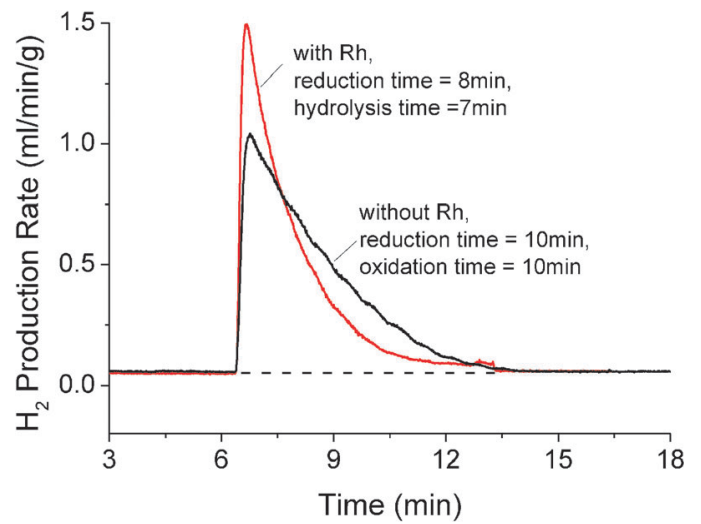

Fig. 13 Impact of the $\mathrm{Rh}$ catalyst on the rate of $\mathrm{H}_{2}$ production for isothermal thermochemical cycling with ceria at $1500{ }^{\circ} \mathrm{C}$, with the reduction $\left(p_{\mathrm{O}_{2}}=\right.$ $10^{-5}$ atm, balance $\mathrm{Ar}$ ) and hydrolysis $\left(p_{\mathrm{H}_{2} \mathrm{O}}=0.15\right.$ atm, balance Ar) times indicated. The rates shown are implied based on the $\mathrm{O}_{2}$ productivity of each case to allow for the stoichiometric ratio of $\mathrm{H}_{2}: \mathrm{O}_{2}=2: 1$ of gas productivities. The level of the $\mathrm{H}_{2}$ baseline measured by mass spectroscopy is indicated by the horizontal dashed line for comparison.

fuel productivity, we estimate that the highest fuel production rates under isothermal cycling of undoped, uncatalyzed ceria at

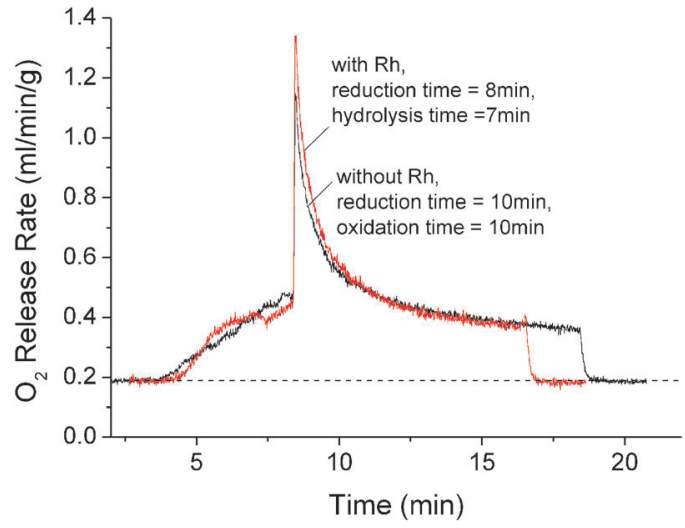

Fig. 14 Impact of the $\mathrm{Rh}$ catalyst on the rate of $\mathrm{O}_{2}$ release for isothermal thermochemical cycling with ceria at $1500{ }^{\circ} \mathrm{C}$, with the reduction $\left(p_{\mathrm{O}_{2}}=\right.$ $10^{-5}$ atm, balance $\mathrm{Ar}$ ) and hydrolysis $\left(p_{\mathrm{H}_{2} \mathrm{O}}=0.15 \mathrm{~atm}\right.$, balance $\mathrm{Ar}$ ) times indicated. The level of the $\mathrm{O}_{2}$ baseline measured using mass spectroscopy is indicated by the horizontal dashed line for comparison.

$1500{ }^{\circ} \mathrm{C}$ will occur for a cycle period of $12.8 \mathrm{~min}$ and will yield approximately $1.96 \mathrm{ml} \mathrm{H}_{2} \mathrm{~g}^{-1}$ per cycle. This corresponds to a time-averaged hydrogen production rate of $\sim 9.2 \mathrm{ml} \mathrm{g}^{-1} \mathrm{~h}^{-1}$. In the case of the two-temperature cycle, we estimate the behavior under a temperature swing between 1500 and $800{ }^{\circ} \mathrm{C}$ as follows. The time required to achieve close-to-full reduction at $1500{ }^{\circ} \mathrm{C}$ is, from the results of Fig. 12, approximately $30 \mathrm{~min}$, and that to achieve close-to-full hydrolysis at $800{ }^{\circ} \mathrm{C}$ is, on the basis of our previous studies, approximately $10 \mathrm{~min} .{ }^{6,7}$ The time required for ramping up and down between the two temperatures is a variable depending on the type of reactor utilized. In a tube reactor heated by an infrared image furnace, ${ }^{6}$ the rate can be as high as $1000{ }^{\circ} \mathrm{C} \mathrm{min}^{-1}$, whereas in solar reactor average rates of about $50{ }^{\circ} \mathrm{C} \mathrm{min}^{-1}$ have been achieved. ${ }^{7,11}$ These time scales, in combination with the thermodynamic prediction of $8.6 \mathrm{ml} \mathrm{g}^{-1}$ of hydrogen production, imply an overall rate of 7.6-12.5 $\mathrm{ml} \mathrm{g}^{-1} \mathrm{~h}^{-1}$. With these numbers, the isothermal cycle provides an overall rate that is comparable to that of conventional temperatureswing cycling.

\section{Conclusions}

The possibility of producing chemical fuel (hydrogen) from solar-thermal energy input using an isothermal cycling strategy has been considered theoretically and demonstrated experimentally. A closed-system analysis shows that, under the idealized assumptions of zero heat loss to carrier gases, the efficiency is maximized in the low- $r_{\mathrm{H}_{2} \mathrm{O}}$ limit, i.e., the quantity of ceria is infinite relative to the quantity of steam. This idealized behavior occurs because there is no penalty, in the absence of thermal cycling, for maintaining the oxide at high temperature. The analysis further shows that the efficiency increases monotonically with increasing temperature. This trend, which is also expected for two-temperature cycling, results from the super-linear sensitivity of the change in oxide non-stoichiometry to temperature. Evaluation of the enthalpy inputs for fuel production indicates the significance of heat 
recovery from steam, in addition to that from carrier gases, in determining efficiencies. The experimental results show that time-averaged, isothermal fuel production rates over ceria (at $1500{ }^{\circ} \mathrm{C}$ ) are comparable to those estimated for conventional two-temperature cycling (between 1500 and $800{ }^{\circ} \mathrm{C}$ ) and similar gas conditions, despite the lower fuel production per cycle of the former. In addition, $\mathrm{Rh}$ as a catalyst significantly enhances the rate of the relatively fast hydrolysis reaction but has only slight impact on the relatively slow reduction reaction. The comparable kinetics of the two cycling strategies indicates that, although the computed thermodynamic efficiencies do not provide the absolute values for realistic reactors, they provide a meaningful basis for comparing the two approaches. In general, the isothermal approach achieves a higher efficiency at higher temperatures. Furthermore, high efficiencies under two-temperature cycling are possible only when high levels of heat recovery from the solid state (i.e., the oxide) are achieved, a technically challenging task. The isothermal approach not only eliminates the need for solid state heat recovery, it also eliminates the mechanical stresses associated with rapid temperature swings, suggesting that reactors incorporating this approach will not only be more efficient, they will also be more robust than those relying on thermal cycling.

\section{Acknowledgements}

This study is based upon work supported by the National Science Foundation under Grant No. CBET-1038307 and the US Department of Energy ARPA-e program under Grant No. DE-AR0000182 (sub-award No. A002601001). The authors would like to thank Stephen Wilke and Dr. Timothy Davenport for useful discussions.

\section{References}

1 S. Abanades and G. Flamant, Thermochemical hydrogen production from a two-step solar-driven water-splitting cycle based on cerium oxides, Sol. Energy, 2006, 80, 1611-1623.

2 A. Le Gal, S. Abanades and G. Flamant, $\mathrm{CO}_{2}$ and $\mathrm{H}_{2} \mathrm{O}$ splitting for thermochemical production of solar fuels using nonstoichiometric ceria and ceria/zirconia solid solutions, Energy Fuels, 2011, 25(10), 4836-4845.

3 H. Kaneko, T. Miura, H. Ishihara, S. Taku, T. Yokoyama, H. Nakajima and Y. Tamaura, Reactive ceramics of $\mathrm{CeO}_{2}-\mathrm{MO}_{x}(\mathrm{M}=\mathrm{Mn}, \mathrm{Fe}, \mathrm{Ni}, \mathrm{Cu})$ for $\mathrm{H}_{2}$ generation by twostep water splitting using concentrated solar thermal energy, Energy, 2007, 32(5), 656-663.

$4 \mathrm{H}$. Kaneko, H. Ishihara and S. Taku, Cerium ion redox system in $\mathrm{CeO}_{2}-x \mathrm{Fe}_{2} \mathrm{O}_{3}$ solid solution at high temperatures (1273-1673 K) in the two-step water-splitting reaction for solar $\mathrm{H}_{2}$ generation, J. Mater. Sci., 2008, 43, 3153-3161.
5 H. Kaneko, S. Taku and Y. Tamaura, Reduction reactivity of $\mathrm{CeO}_{2}-\mathrm{ZrO}_{2}$ oxide under high $\mathrm{O}_{2}$ partial pressure in two-step water splitting process, Sol. Energy, 2011, 85, 2321-2330.

6 W. C. Chueh and S. M. Haile, A thermochemical study of ceria: exploiting an old material for new modes of energy conversion and $\mathrm{CO}_{2}$ mitigation, Philos. Trans. R. Soc., A, 2010, 368, 3269-3294.

7 W. C. Chueh, C. Falter, M. Abbott, D. Scipio, P. Furler, S. M. Haile and A. Steinfeld, High-flux solar-driven thermochemical dissociation of $\mathrm{CO}_{2}$ and $\mathrm{H}_{2} \mathrm{O}$ using nonstoichiometric ceria, Science, 2010, 330, 1797-1801.

8 P. Furler, J. Scheffe, M. Gorbar, L. Moes, U. Vogt and A. Steinfeld, Solar thermochemical $\mathrm{CO}_{2}$ splitting utilizing a reticulated porous ceria redox system, Energy Fuels, 2012, 26(11), 7051-7059.

9 R. B. Diver, J. E. Miller, M. D. Allendorf, N. P. Siegel and R. E. Hogan, Solar thermochemical water-splitting ferritecycle heat engines, J. Sol. Energy Eng., 2008, 130, 041001.

10 Personal communications with Lipinski and Davidson, University of Minnesota.

11 R. B. Diver, J. E. Miller, N. P. Siegel and T. A. Moss, Testing of a CR5 Solar Thermochemical Heat Engine Prototype, Proceedings of the ASME 4th International Conference on Energy Sustainability, 2010, vol. 2, pp. 97-104.

12 Y. Hao, W. C. Chueh and S. M. Haile, Isothermal Synthesis of Fuels with Reactive Oxides, International Patent Application WO 2012/178159 A1, 2012.

13 E. A. Fletcher and R. L. Moen, Hydrogen and oxygen from water, Science, 1977, 197, 1050-1056.

14 G. F. Hewitt, Heat Exchanger Design Handbook, Begell House, New York, 2009.

15 R. J. Panlener, R. N. Blumenthal and J. E. Garnier, A thermodynamic study of nonstoichiometric cerium dioxide, J. Phys. Chem. Solids, 1975, 36, 1213-1222.

16 HSC Chemistry 5.11, Outokumpu Research Oy, Pori, Finland, A. Roine.

17 A. Steinfeld, Solar hydrogen production via a two-step water splitting thermochemical cycle based on $\mathrm{Zn} / \mathrm{ZnO}$ redox reactions, Int. J. Hydrogen Energy, 2002, 27(6), 611-619.

18 J. R. Scheffe and A. Steinfeld, Thermodynamic analysis of cerium-based oxides for solar thermochemical fuel production, Energy Fuels, 2012, 26(3), 1928-1936.

19 J. Lapp, J. H. Davidson and W. Lipinski, Efficiency of twostep solar thermochemical non-stoichiometric redox cycles with heat recovery, Energy, 2012, 37(1), 591-600.

20 W. C. Chueh and S. M. Haile, Ceria as a thermochemical reaction medium for selectively generating syngas or methane from $\mathrm{H}_{2} \mathrm{O}$ and $\mathrm{CO}_{2}$, ChemSusChem, 2009, 2(8), 735-739.

21 M. Kamiya, E. Shimada and Y. Ikuma, Oxygen self-diffusion in cerium oxide, J. Ceram. Soc. Jpn., 1998, 106, 1023-1026. 